\title{
The Experience of the School Bullying Prevention in the Teenage Environment: Gender Aspect
}

\author{
Ksenia S. Shalaginova* \\ Svetlana A. Cherkasova
}

Sergei K. Haidov

Maxim A. Basin

Tula state pedagogical University L. N. Tolstoy, Russian Federation *Corresponding Email: shalaginvaksenija99@yandex.ru

\author{
Doi:10.5901/mjss.2015.v6n6s7p269
}

\begin{abstract}
The article presents the experience of working with teenagers on the prevention of school violence manifestations. Activities for the prevention of bullying and its retention at a socially acceptable level by removing or neutralizing the causes generating it are more meaningful and effective taking into account gender-specific manifestations of school bullying. This situation requires the maintenance of a separate work with teenage boys and girls because the specifics of their behavior are quite different. The aim of the study is to develop and to test technology of the psychologist's activity for the bullying prevention in the teenage environment based on the gender approach. At the same time, we believe that bullying prevention (efforts to prevent it or withhold at a socially acceptable level by removing or neutralizing the causes generating it) will help to lower the scale of the negative phenomenon, to reduce the amount of "aggressors" and "victims" involved in it. Comparative analysis of results of ascertaining and control phases of the experiment allows drawing conclusions on the positive dynamics in the sample, identifying the behavior peculiarities in a situation of possible bullying of boys and girls and developing a set of preventive measures based on them, allows bringing such activities to an entirely new level.
\end{abstract}

Keywords: higher education, Russian education, gender aspect

\section{Introduction}

School bullying is seen in the modern world as a serious social and pedagogical problem. In the West, the problem of bullying is a number one problem. In many European countries and the United States, it is associated with the state interests. The EU member states have repeatedly held meetings at the level of Education Ministers and have developed legislative measures for its prevention. The most effective antibilling program initiated by Olweus (1999) has been successfully used in Norway where it has been given the status of a priority national program since 2001 . Western researchers have presented statistics, described the options of bullying manifestations, psychological characteristics of victims and instigators, assistance rendering, numerous anti-bullying companies have been developed. However, in spite of this, a problem of violence and cruelty in educational institutions is still current. January, 27 is marked in the calendar as the International Day against bullying.

In Russian psychology until recently, bullying is not considered as the specific situation of social interaction. Some of its elements were described as 'manifestations of aggression', 'victimization', 'low social status in a group'. The problem of school violence in domestic science for a long time belonged to the category of problems that used to be hushed up, to pretend that nothing was happening. According to the studies, about $82-85 \%$ of class students are directly or indirectly involved in bullying (Salmivalli, 2010).

Until recently, both in domestic and in Western practice the problem of bullying is predominantly classified as 'male', as for many it is males who are more aggressive in comparison to females. It is believed that boys are more prone to acts of aggression but it is not fully true; the girls' aggression is just different. The difference between the aggressiveness of the sexes is especially noticeable between ten and fourteen years when girls go further in their mental and physical development than boys. According to the majority of scholars, the difference in aggressive behavior between girls and boys has been more and more decreasing; in recent years, girls have begun to exhibit aggressive 
behaviors.

The aim of the study is to develop and to test of the technology of the psychologist's activity for the bullying prevent in the teenage environment with a gender perspective. At the same time, we believe that bullying prevention (efforts to prevent or towithhold it at a socially acceptable level by removing or neutralizing the causes generating it) will help to lower the scale of the negative phenomenon, to reduce the amount of "aggressors" and "victims" involved in it.

\section{The Gender-specific Manifestations of Bullying - analysis of Modern Studies}

An analysis of the literature on the study topic has allowed identifying some gender-specific bullying manifestations in the teenage environment requiring accounting in preventive practice.

According to the observations of the Norwegian scholar and educator D. Olweus, young men act as aggressors more often than girls do. Although, girls demonstrate significantly less aggression and violence; it does not mean that they are not involved in conflict situations (Olweus, 1995). Gossips, verbal insults and boycotts are the most common forms of bullying among girls. Such recurring offensive actions may harm the physical and emotional development of the child, against whom it is directed (Furmanov, 2002).

According to Chizhova \& Kalinina (2003), girls do not concede to boys in terms of cruelty. It is often girls who act as initiators of classmates bullying. Though, a few years ago such behavior did not fit to a positive image of femininity, but now, due to the weakening of gender polarization, it appears more and more openly. Victims of female bullying on the grounds of jealousy and rivalry increasingly become other girls.

In our opinion, it does not cause difficulties to explain the manifestation of these forms of bullying among girls. Everything is quite logical. Firstly, women are physically weaker, so it makes no sense to use direct physical aggression (although, on the other hand, who will manage to stop them to apply it in conflicts with representatives of their gender?). Secondly, the use of direct physical and partly direct verbal aggression does not fit the image of women as a gentle, soft, mild, sympathetic creature. Women are embarrassed by public acts of aggression. Girls are more sensitive and impressionable; the brutal manifistation of aggression is usually abhorrent for them. Therefore, they replace very early physical aggression by verbal one and some girls have accustomed to camouflage aggressiveness by irony and sarcasm since childhood. It looks softer, but it hurts stronger.

Female sex sooner learns to control their aggression, that is why it becomes elective too early and beats right on target. Girls are clearly direct their aggression against a specific person and exactly to his/her psychologically vulnerable point. Girls' aggressiveness is often veiled and seemingly less efficient but more effective. According to British psychologist, bullying by girls is especially dangerous. Monitoring the behavior of 11-year-old primary school leavers for 16 months, Valerie Besag has found that if boys show only their physical superiority when choosing a child as a "scapegoat", the girls start a real psychological war against their victims (Besag, 1989).

Psychologists have found that children exposed to harassment by a group of girls, in the future, have difficulties in building relationships, they tend to be overprotective of their children, and are often victims of bullying in the workplace.

According to research conducted at the Åbo Akademi University, the University of Stavanger, Institute of Clinical Medicine in Tromsø, the boys find themselves in a situation of bullying in two and a half times more often than girls. Meanwhile, the long-term impact is more difficult for girls. They more likely develop post-traumatic stress disorder reaction of an organism to trauma - than boys. Such disorder is common among victim of terrorist attacks, veterans who came from the war, and people having experienced war, genocide, or natural disasters. Clinical symptoms of the disorder occur in about $28 \%$ of boys and $41 \%$ of girls who have been bullied at school.

Girls experienced the role of victims being adults often lie in psychiatric hospitals and receive antipsychotics, tranquilizers and antidepressants; and it does not depend on whether they were mentally healthy at the beginning of bullying or not. As we noted above, until recently, a problem of bullying has been considered as predominantly 'male' because for many people 'it is obvious' that males are more aggressive compared to females.

Bullying is significantly more common among boys of all ages; it is a 'normal' aspect of boyish culture. Aggression is a part of the male stereotype of behavior; it is more often expected and encouraged. The differences in the behavior of boys and girls are already evident in the second year of life. The boys from an early age should be able to fight back, they are taught and encouraged to deal with offenders on their own. The girls are blamed for excessive activity, aggressiveness, and desire to command.

Boys bully others two to three times more often than girls, and they are the main victims of bullying. Bullying of girls by boys, one of boys by girls and one of girls by girls occur much less frequently. Perhaps, this is associated to the fact that girls (but not all!) are able to better control their aggression and to find other ways to resolve conflicts. According to the observations of the Norwegian scholar and educator Olweus (1995), young men more often act as aggressors than 
women.

Gender-specific manifestations of bullying, as we mentioned above, find some explanation in the so-called 'gender roles' that encourage the manifestation of male aggression in some forms, while the aggressiveness of women is not welcome. The men are often forced into the surrounding aggression calling into question their social status or selfesteem. Women, on the contrary, are embarrassed if they have to be aggressive publicly. Men prefer roles that require the manifestation of aggression (in the military or sports fields), while for the majority of women aggressiveness is absolutely inappropriate (e.g., mother, secretary, teacher) (Semenuk, 1998).

Boys' aggression is usually manifested in more open and rude manner, it is less controllable; and boys start to monitor it later than girls. Boys badly control their aggression; it is their more generalized and lavishly splashed indiscriminately on everyone around. In addition, there is still a stereotypical social opinion that girls ought not to express their aggression, and therefore they start to learn to restrain it much earlier. For example, it is said "Go and fight back" to a boy in response to a complaint that he is hurt or beaten; such advice is less often given to a girl: it is generally recommended not to get involved and step aside.

The difference between male and female bullying can be connected with the fact that boys and girls may have the different criteria of popularity. For example, a study of 400 Greek students of 4-6 forms (Andreu, 2006) has showed that both explicit and conditional aggression reduces the popularity of girls, whereas boys' explicit aggression makes them more popular. At school, a boy does not only learn but also continues to design his own masculinity, the main principle is to do nothing 'girlish'. A fighter who violates school rules and is afraid of nobody becomes very often a hero and is admired, whereas a "good boy" and high achiever is a despised mother's darling.

Secondly, bullies become a normative way of a "real man" whose level everyone needs to attain. Brought up in such a spirit, boys do not know how to communicate equally with girls and try to solve all the others conflicts by means of force that makes them dangerous for others and for themselves. In its turn, the boys who have become victims of bullying are embarrassed to seek assistance from adults and try to protect themselves with the help of the reverse aggression, which often increases their social and psychological difficulties.

In Portugal in the survey of more than 4,000 children from ten to twelve years old in 10 secondary schools it has been found that boys and people from the lower social strata are in high-risk situations with regard to bullying.

In the Brazilian high school students in whose culture machismo (the ideology of male supremacy) occupies an important place, bullying is much more common among boys and is closely related to sexual harassment. At the same time, the intensity of bullying correlates with the general bad behavior, and many things depend on the degree of teachers' intolerance to bullying.

Australian schoolboys are also more involved in bullying than girls. The dissemination of general negative attitude of boys to potential victims of bullying and the belief that their friends accept such behavior positively contribute to bullying spreading. It is interesting that the parents' negative attitude to bullying affects only girls; in these matters boys are guided only by their own environment's opinion.

In recent years, Japanese pedagogues are much concerned with bullying. Survey of 2923 Japanese students in $7-$ 9 forms on psychosocial factors of bullying has highlighted such factors as the impact of deviant peers on adolescent and poor self-control over their own aggressiveness and impulsiveness but at the opposite pole there is a lack of assertiveness and inability to resist the pressure.

The consequences of bullying for boys are extremely serious. A study of 1655 South Korean schoolchildren of the seventh and eighth forms has showed that it significantly increases the statistic risk of suicide. Bullying does not only complicate the boy's life but also has long-term psychological consequences. In Finland, the 2540 boys were examined at 8 years old and 18-23 years old (during the recruitment). In $28 \%$ of the boys who often had the experience of bullying and/or victimization in elementary school, showed different psychiatric problems 10-15 years later: boys who were only tormentors manifested antisocial personal traits, drug addiction, depression and anxiety. Those who were only victimizated were the most disturbing. The alternation of bullies and victims roles correlates with antisocial personality type and anxiety.

When a bully torments another aggressive boy, there is sometimes peculiar based on mutual aggression partnership between them; although the boys are constantly bullying each other, it does not prevent them to be friends. However, the victims of bullying are most often disturbing, socially vulnerable, silent and restrained children. Chronic victims of bullying are physically weaker and more sensitive than the other boys; they are more anxious, lonely and prone to depression. It makes them the easy prey for aggressive peers or older boys and dependent status, in its turn, lowers their self-esteem and increases depression. More vulnerable boys are doomed to be victims because bullies know that they cannot stand up for themselves.

Using a gender perspective enables to destroy the cultural constraints of development, to reveal the inner potential 
of the individual and to create conditions for girls and boys's self-realization. Taking into consideration of gender features gives, on the one hand, the opportunity to show an individual approach to the student, on the other hand, it opens up new possibilities for the studying of aggression, its prevention and correction of its destructive manifestations.

\section{Research Methodology}

As the methods of investigation, we have used the following: theoretical analysis of the psychological and pedagogical literature on research topic; psychological and pedagogical experiment in the unity of the three phases (summative, forming and controlling); method of data processing: qualitative and quantitative analysis of the study results.

In order to identify gender-specific predisposition to bullying (mainly in the role of instigators, the bullying initiators), we picked up a package of diagnostics tools: the Buss-Durkey Inventory; assessment of the level of group cohesion in the class by C.E. Seashore (1966); types of behavior in the conflict by K. Thomas (2001); diagnostic technique of selfassessment of mental states by Eysenck and Wilsson (2000); test "Level determination of conflict resistance" by Fetiskin et al. (2002); methods of "interference" diagnosis in emotional contact establishing by Boyko (2008); method of diagnosing the empathic abilities level by V.V. Boyko, express questionnaire "Index of tolerance" by Soldatova et al. (2008).

The study took place in the academic year of 2014-2015 on the basis of three schools and two gymnasiums in Tula. In total, the study involved about 320 teenagers (152 boys and 168 girls).

\section{Results and Discussion}

Results analysis of the summative stage of the experiment allowed drawing the following conclusions.

Using the Buss-Durkey Inventory there were identified above average performance on the scales of physical, indirect, verbal aggression, suspicion and guilt for groups of boys and girls. It was identified the most problematic indicators $-80 \%$ of girls and $50 \%$ of boys are inclined to verbal forms of expression of the aggression; $60 \%$ of girls and $30 \%$ of boys show suspicion; $60 \%$ of girls and $30 \%$ boys tend to the indirect aggression; $40 \%$ of boys and $10 \%$ of girls use physical force as a way to throw out the aggression, "to solve the problem"; $50 \%$ of boys and $60 \%$ of girls feel guilty; $60 \%$ of both boys and girls experience increased irritation.

Test by K. Thomas has allowed to determine the dominant style of a person's behavior in a conflict situation. The most preferred tactics of behavior in the conflict is "avoiding", $40 \%$ of boys and $30 \%$ girls have inclined to it; the second place are taken by the "rivalry" - $30 \%$ of boys and $55 \%$ girls; $20 \%$ of boys bent to adaptation; about $25 \%$ of girls and boys - to compromise; $10 \%$ of boys and $5 \%$ of girls uses cooperation.

Diagnostic technique of self-assessment of mental states by $G$. Eysenck allowed considering the measure of aggressiveness (stable personality characteristics) for boys and girls. Based on the results, we can conclude that $30 \%$ of boys and $20 \%$ of girls have a high aggressiveness, these children have problems with relationships with other people.

Technique of group cohesion level by $\mathrm{C}$. Seashore allows, on the one hand, talking about the high rates of solidarity, on the other hand, passive attitude to the participattion in extracurricular activities, community life should be noted at $60 \%$ of boys and $20 \%$ of girls. Most of the boys (55\%) has a low level of conflict resistance.

Girls (60\%) have the average level of conflict resistance. Most respondents teenagers - boys (85\%) and about $75 \%$ of girls - are on level 4 of an emotional efficiency. To some extent, emotions complicate the interaction with partners for many boys and girls. Emotions usually do not interfere with the relationship with partners only for some girls. Most boys have revealed such "interferences" in communication as inflexibility, underdevelopment, inexpressive emotions (45\%), dominance of negative emotions and inability to manage emotions (15\%). While girls show such "interferences" as: inability to manage emotions and to dose them, inappropriate display of emotions (65\%), inflexibility, underdevelopment, inexpressive emotions (25\%), dominance of negative emotions and reluctance to draw nearer to other people on an emotional basis (30\%). Teenage boys have badly expressed rational channel of empathy (45\%), emotional (25\%), intuitive (25\%), penetrating power of empathy (10\%) and there are no identification in empathy (0\%). At the same time, the girls have not developed an intuitive channel of empathy (25\%) and the penetrating power of empathy $(35 \%)$. Thus, the majority of the boys (75\%) have revealed a lower level of empathy, and the majority of girls have the average level of empathy (55\%). The majority of female (95\%) and male representatives (100\%) has the average level of tolerance.

Based on the results of the study, we have developed a prevention program designed according to adolescents and gender characteristics of students.

Objectives of the program: to understand psychological essence of aggression, aggressive behavior, its specificity 
by adolescents, to develop skills of secure and adequate expression of anger; to creat conditions for the study and understanding of one's own emotions and the emotions of other people; to develop the ability to understand one's own feelings; to realize the negative emotions, to elaborate them and to act them out;-- to optimize the interaction of teenagers in the team; to form skills of constructive conflict resolution; to increase the level of tolerance empathy; to develop the need for further self-development and realization of personal potential.

When organizing activities with teenage boys, special attention should be paid to their motor activity. Boys are inherently less restrained and unable to control their behavior with the same success as the girls. A long stay in a sitting position has a greater negative impact on boys than on girls. For this reason, when working with boys, it is necessary to hold a small warm-up, movement exercises.

In working with the boys, the emphasis is done on the development of skills of secure and adequate anger expression, on adolescents' understanding of psychological essence of aggression, its specificity, peculiarities, on optimizition of the teenagers' interaction in a group, on increased empathy and tolerance, 'emancipation' of the emotional sphere.

Adolescent girls are sometimes notable for their indecision. When conducting preventive activities, it should be created a situation of success for girls to 'push' them to discuss and answer. For this purpose, such techniques are used as questions for reflection (without the correct answer), group work where each girl gets a task and contributes to the work, etc.

When working with girls, the focus is to develop the ability to understand their feelings, awareness of the negative emotions, their elaboration and acting out, the ability to adequately show and restrain negative emotions towards other people, to decline indirect verbal aggression, to increase empathy, to form skills of constructive conflict resolution.

Classes are designed for two groups and assume a unit of joint activities, training units separately for boys and separately for girls. The time of each lesson is 90 minutes.

As a basis for the development of preventive programs, we used psychological group training. Psychological group training is a method of intentional human changes aimed at their personal and professional development through the acquisition, analysis and re-evaluation of their own experiences in group interaction. The following Table 1 shows an exemplary structure of each lesson.

Table 1. Exemplary structure of the lesson

\begin{tabular}{|c|c|c|c|c|}
\hline № & Stages & Time, $\min$ & Objectives & Means of realization \\
\hline 1. & Greeting & 5 & Beginning of the lesson & A certain ritual \\
\hline 2. & Social circle & 15 & Mindset on the interaction & The topic of the lesson determines the content \\
\hline 3. & Warm-up & 15 & Detente, relaxation & Motion games \\
\hline 4. & Work on the lesson topic & 35 & Tasks correspond to the lesson topic & Elements of games, conversation, training \\
\hline 5. & Completion & 15 & Analysis of the work, reflection & Exercise and games \\
\hline 5. & Farewell & 5 & Ending of the lesson & A certain ritual \\
\hline & Total: & \multicolumn{3}{|c|}{90 minutes } \\
\hline
\end{tabular}

\section{Conclusion}

Comparative analysis of summative and control phases' results of the experiment allows drawing conclusions about the positive dynamics in the sample.

Through the decrease in performance above average on the scale of physical aggression in $10 \%$ of boys and girls; indirect aggression in $20 \%$ of boys and $10 \%$ of girls; verbal aggression in $20 \%$ of boys and $30 \%$ of girls; irritability in $20 \%$ of girls and $10 \%$ of boys; guilt in $10 \%$ of boys and girls. The level of verbal aggression is reduced in boys and girls alike; the level of physical aggression among girls has decreased by $20 \%$, among boys - by $10 \%$; emotional aggression in girls has decreased by $20 \%$, in boys - by $10 \%$; self-agression among girls has decreased by $30 \%$ and among boys - by $20 \%$.

Through boys's manifestation of this style of behavior in conflict resolution as a compromise $-15 \%$ and increase in performance of collaboration by $5 \%$. Manifestation of leading style of girls' behavior - the compromise - $35 \%$, the rate of avoidance has decreased by $10 \%$, the competition - by 15\%; cooperation has increased by $10 \%$; a tool as a way of behavior in the conflict has appeared $-5 \%$.

Level of group cohesion in class for all students is in a range from medium to high above. At the controlling phase of the experiment, $45 \%$ of boys have identified average level of conflict resistance and $35 \%$ - low. These results differ significantly from the results of summative stage. Boys are marked by the increase in the number of respondents with an average level of conflict resistance, the reduction of the number of subjects with low levels of conflict stability; a very low 
level of conflict stability in the male sample at this stage is not revealed. The girls at the controlling stage have obtained the following results - in most study subjects conflict resistance is average of $55 \%$, a high level is inherent to $20 \%$, a low level of conflict resistance is in $25 \%$ of the girls participating in the study.

Rational channel of empathy is detected in $65 \%$ of boys interviewed, a $20 \%$ increase compared to the summative stage, and $55 \%$ of girls surveyed. Emotional empathy channel is at $25 \%$ of boys, which remained unchanged, and $80 \%$ of the female a $10 \%$ increase compared to the summative step. Intuitive empathy channel is at $35 \%$ of boys and $30 \%$ of girls noted this type. Thus, in male and female sample number of respondents has increased by $10 \%$. Purposes promoting the empathy have been found in $35 \%$ of males and $45 \%$ of females. These figures have also increased in the respective male and female sample. Penetration in empathy has been found in $25 \%$ of boys and $60 \%$ of girls. The number of teenagers characterized by the presence of this type of empathy has increased in male and female sample. Identification of empathy at the controlling stage of the experiment has been found in $20 \%$ of boys and $55 \%$ of girls. This figure has risen in girls who are characterized by identification in empathy in the female sample; it has increased by $15 \%$.

At the controlling phase of the experiment, teenage boys have been identified by such "interferences" in establishing emotional contact as inflexibility, underdevelopment, and inexpressive emotions - 25\%. The presence of positive dynamics in a sample of young people should be noted, as this figure is $20 \%$ less than at the summative phase. There is a slight decrease (5\%) in the number of young people who are dominated by negative emotions The sample of girls has been noted by positive dynamics in the emergence of such "interferences" in establishing emotional contact as the inability to manage emotions, dose and inappropriately display emotions (it has decreased by $20 \%$ ), inflexibility, underdevelopment, inexpressive emotions (it has lowered by 10\%), the dominance of negative emotions and unwillingness to get close to people on an emotional basis (it has reduced by $5 \%$ ). Thus, compared to the summative phase, the number of teenagers on all previously "identified interferences" has decreased.

As a result of the controlling phase of the experiment, $20 \%$ of the surveyed boys are at level 5 of emotional effectiveness in communication, $45 \%$ - at level 4 and $35 \%$ - at level 3 . Girls were allocated as follows: $10 \%$ - at level 5 of emotional effectiveness, 35\% - both at level 4 and at level 2, 20\% - at level 3. All figures have been significantly changed compared to summative phase.

The average level of empathy has been identified at $55 \%$ of boys, which is $20 \%$ higher than at the summative phase, $45 \%$ of the low level of empathy, which is $30 \%$ less compared to the summative phase. Most girls - $75 \%$ - have the average level of empathy. The number of respondents with an average level of empathy in the female sample has increased by $25 \%$, with a low level $-25 \%$ that is lower by $15 \%$ and $10 \%$ has a very low level, that has remained unchanged.

A comparative analysis of the results of diagnostic by the express-questionnaire 'Tolerance index' at summative and controlling phases of the experiment lets talk about the positive dynamics at the sample of girls only. $5 \%$ of the girls in the summative phase have revealed a high level of tolerance which has not been found at the summative phase Thus, the majority of respondents in the samples of girls and in the sample of boys - $90 \%$ and $100 \%$, respectively, have an average level of tolerance and show a combination of both tolerant and intolerant features. In some social situations, they behave tolerantly, in others - they may manifest intolerance.

The analysis of the results of the conducted study allows speaking about effectiveness and appropriateness of the gender specificity in the prevention of school violence. Identification of the behavioral peculiarities in a situation of possible bullying of boys and girls and development of a set of preventive measures based on them allow bringing such activities to an entirely new level.

\section{Acknowledgment}

Research is funded by the RHF, project 14-16-71011a/L

\section{References}

Besag, V. (1989). Bullies and Victims in Schools, Milton Keynes: Open University Press. Boyko, V.V. (2008). Psychoenergetics. St. Petersburg, Peter.

Chizhova, S.Yu., \& Kalinina, O.V. (2003). Children aggressiveness. Yaroslavl: Akademiya razvitiya.

Eysenck, G. \& Wilsson, G. (2000). How to measure the identity of Moscow. Kogito Center.

Fetiskin, N.P., Kozlov, V.V., \& Manuilov, G.M. (2002). Socio-psychological diagnosis of personality development and small groups. Moscow, Publishing House of the Institute of Psychotherapy.

Furmanov, I.A. (2002). Children aggressiveness. Moscow.

Olweus, D. (1995). Bullying or peer abuse in school: intervention and prevention. In G. Davies et al. (Eds.), Psychology, law and criminal 
justice: international developments in research and practice (pp. 248-263). Berlin: Walter de Gruyter.

Olweus, D. Sweden (1999). In: R., Catalano, J., Jungertas, Y., Morita, D., Olweus, P., Slee, \& P. K., Smith. The nature of school bullying: a crossnational perspective. (pp. 141-145). London, UK: Routledge.

Salmivalli, Ch. (2010). Bullying and the peer group: a review. Aggression and violent behaviour, 15, 112-120.

Seashore, C.E. (1966). Seashore-Test fur musikalische Begabung. Toronto.

Semenuk, L.M. (1998). Psychologicheskie aggressivnogo povedeniya podrostkov i usloviya korrecci. Moscow.

Soldatova, G.U., Shaygerova, L.A., Prokofeva, T.Yu, \& Kravtsova, O.A. (2008). Psychodiagnostics of individual's tolerance. Moscow, Misl.

Thomas, K. (2001). A test that describes the behavior. In: A.A. Karelin. Psycological tests. (pp. 69-77). Moscow. 